\title{
TESTE CONCEITO DA BEBIDA KOMBUCHA: UM ESTUDO DE MARKETING
}

BARBOSA, Sara Patrícia Chalis ${ }^{1}$

COSTA, Barbara Regina Lopes ${ }^{2}$

ARAÚJO, Richard Medeiros de ${ }^{3}$

Recebido em: 2020.03 .27

Aprovado em: 2020.04.28

ISSUE DOI: $10.3738 / 1982.2278 .3764$

\begin{abstract}
Resumo: Este paper objetivou executar um teste de conceito de produto para avaliar sua aceitação e seu potencial de mercado. Um produto natural que ressurgiu, com a busca social por uma alimentação mais saudável, foi o Kombucha, uma bebida milenar, que promete vários benefícios à saúde, mas ainda é pouco conhecida. Metodologicamente, foi uma pesquisa exploratória, com levantamento de campo junto a uma amostra não probabilística que degustou o Kombucha e em seguida respondeu um questionário estruturado. Para assegurar que o teste conceito ocorresse de forma adequada organizou-se uma sistematização com três etapas/procedimentos para a devida coleta de dados. Os dados foram tratados quantitativamente e trouxeram perspectiva positiva para quem pretende comercializar a bebida, que recebeu os adjetivos gostoso, saboroso, refrescante e diferente, bem como sugestões mediantes aos relatados dos degustadores, que destacam o cheiro e a acidez, como pontos fracos do produto.
\end{abstract}

Palavras chaves: Alimentação Saudável; Alimento Funcional; Chá; Kombucha; Teste Conceito.

\section{KOMBUCHA DRINK CONCEPT TEST: A MARKETING STUDY}

\begin{abstract}
SUMMARY: This paper aimed to perform a product concept test to assess its acceptance and its market potential. A natural product that resurfaced, with the social search for healthier food, was Kombucha, an ancient drink that promises several health benefits, but is still little known. Methodologically, it was an exploratory research, with a field survey with a non-probabilistic sample that tasted Kombucha and then answered a structured questionnaire. To ensure that the concept test was carried out properly, a systematization was organized with three steps / procedures for the proper data collection. The data were treated quantitatively and brought a positive perspective for those who intend to commercialize the drink, which received the adjectives tasty, tasty, refreshing and different, as well as suggestions based on those reported by the tasters, who highlight the smell and acidity, as weaknesses of the product.
\end{abstract}

Keywords: Healthy Eating, Functional food; Tea; Kombucha, Test Concept.

\section{INTRODUÇÃO}

O consumo exacerbado de alimentos gordurosos e sem nutrientes vem causando várias complicações para a qualidade de vida humana, chegando a ser um problema de saúde pública. Em contrapartida, há um movimento em ascensão de pessoas que buscam por alimentos saudáveis.

O mercado de alimentação saudável está cada vez mais ganhando adeptos, seja por conscientização e mudança no estilo de vida ou até mesmo pelo marketing da vida saudável. De

\footnotetext{
1 Tecnóloga em Gestão Empresarial pela Fatec Indaiatuba

2 Publicitária e Administradora, pós-graduação Lato-sensu em Comunicação Empresarial e em Marketing, mestrado em Administração pela Universidade Municipal de São Caetano do Sul (2005) e doutorado em Administração - Universidad de la Empresa (2016). Professora da FATEC Indaiatuba e Orientadora de Polo da Univesp.

3 Doutor em Administração pelo PPGA/UFRN.
} 
acordo com a agência de pesquisas Euromonitor Internacional, o segmento de alimentação saudável no Brasil deve crescer, em média, $4,41 \%$ por ano até 2021 , sendo que o país é o quarto maior mercado do mundo no setor, movimentando US\$ 35 bilhões por ano, um crescimento aproximado de $12,3 \%$ na última década, $4,3 \%$ maior que a média mundial (E-COMMERCE NEWS, 2019).

Neste segmento encontram-se os vegetarianos que, por opção ou doença que exige restrição alimentar, não comem nenhum derivado de carne e os veganos que buscam eliminar toda e qualquer forma de exploração animal. Segundo a pesquisa feita pela IBOPE Inteligência, em 2018, 14\% da população brasileira se declarava vegetariana, 28 milhões de pessoas aproximadamente. Nesta mesma pesquisa, 55\% dos entrevistados responderam que, independente da sua opção alimentar, consumiria produtos veganos se estivesse melhor indicado na embalagem (IBOPE, 2018).

Assim, quando se trata de alimentação saudável, o mercado registra ampliação da busca por alimentos funcionais, que produzem efeitos benéficos à saúde além das suas funções nutricionais básicas.

Um desses alimentos funcionais é o chá verde (Camellia sinensis), um dos chás mais consumidos no mundo, e um dos compostos do chá é os catequinas, que estimulam o sistema imunológico e reduzem a incidência de certos tipos de câncer e o colesterol. Seguindo esta linha tem-se, o Kombucha, uma bebida natural, feito a partir da fermentação do chá verde (Camellia sinensis), com uma placa gelatinosa, chamada Scoby, uma simbiose de leveduras e bactérias benéficas à saúde que transforma o líquido em uma bebida refrescante levemente gasificada, com um aroma frugal, que fornece diversos ácidos e nutrientes ao organismo. Diversas pessoas têm preparado essa espécie de chá fermentado para beber durante séculos, há mais de 2.000 anos (CONSIGLIO, 2017). E o fato de estar presente na sociedade até hoje é, em si, um testemunho de que as milhares de pessoas de todo o mundo, durante séculos, encontraram nele o seu valor.

A revista Super Varejo (2018) traz uma reportagem relatando que as pessoas estão cada vez mais buscando alternativas de consumo de alimentação natural e uma forte tendência são as bebidas fermentadas, como o Kombucha, que vieram de fora e estão conquistando o paladar dos consumidores. Esta popularidade fez com que muitas universidades pesquisassem mais sobre essa bebida. Uma das universidades é a Universidade Federal de Lavras, em Minas Gerais: o Núcleo de Estudos em Fermentações (Nefer) está buscando a comprovação científica dos benefícios do Kombucha para a saúde, e a professora Rosane Freitas Schwan, coordenadora do núcleo e orientadora dos estudos há três anos, comenta que "apesar de ser uma bebida muito utilizada na China e em outros países, ainda não há muitos dados científicos sobre ela”. O intuito 
da pesquisa é avaliar a microbiota presente quando se utiliza outros chás para a fermentação (MASCARENHAS, 2018, p.1)

Missiaggia (2018) relata que o Kombucha tem ajudado muita gente a mudar de vida e, enquanto por alguns ele é encarado como uma maneira de adotar um estilo de vida saudável, para outros o Kombucha significa uma oportunidade de negócio. Mesmo o Kombucha tendo mais de 2000 anos e sendo um produto inovador em relação aos produtos naturais, podendo substituir o refrigerante tradicional, muitos ainda não conhecem suas promessas de benefícios.

A fim de conhecer a percepção dos entrevistados sobre a 'nova' opção de bebida, Kombucha, o objetivo deste trabalho foi realizar um teste conceito para avaliar a aceitação do produto e seu potencial de mercado junto ao público de Indaiatuba, podendo assim diminuir os riscos e garantir uma melhor oportunidade de mercado para um futuro investidor. Para desenvolver este estudo foi utilizado o método de pesquisa exploratório, por meio de dados secundários publicados em livros, artigos, teses disponíveis em base de dados eletrônicas, para embasar o conteúdo referencial, e também dados primários advindos do teste conceito com aplicação de questionários e tratamento dos dados coletados, com a finalidade de atender ao objetivo do trabalho.

Desta forma, esse estudo procura contribuir com os arcabouços de referências teóricas e empíricas a respeito da bebida Kombucha, bem como sobre o Teste Conceito, uma vez que notase existir pouco repertório acadêmico referente aos temas. A junção dos assuntos Teste conceito da bebida Kombucha, poderá se tornar fonte de informação, análise e estímulo a empreendedores e empresários que ainda não conhecem o potencial da bebida e para futuros estudos sobre os temas. Ao término, esse estudo, embora apresente uma amostra não probabilística, propõe ações para futuros investidores e para novos estudos.

\section{FUNDAMENTAÇÃO TEÓRICA EMPÍRICA}

\section{Mercado de Produtos Saudáveis}

Decerto que a alimentação é uma das atividades humanas mais importantes, não só por razões biológicas, mas pelos recursos econômicos envolvidos na alimentação, e em termos de mercado atinge um montante bastante superior quando comparado com outros setores da economia (PROENÇA, 2010).

A nutrição, saúde, bem-estar físico e mental do indivíduo estão relacionados diretamente com a boa alimentação, que tem um papel fundamental na prevenção e no tratamento de doenças. Há milhares de anos, Hipócrates já afirmava: “que teu alimento seja teu remédio e que teu 
remédio seja teu alimento". O equilíbrio na dieta é um dos motivos que permitiu ao homem ter vida mais longa neste século (RECINE, RADAELLI, 2014, p. 05).

Os consumidores, cada vez mais informados e preocupados com a saúde, estão buscando por uma alimentação mais saudável, não só para manter o equilíbrio corporal, mas também pela melhoria da qualidade de vida e por uma expectativa de longevidade. Conhecendo opções de alimentos saudável este consumidor é atraído pelo valor da inovação e não se importa em pagar um pouco a mais se o custo-benefício lhe agradar (SALGADO, 2017).

Pimentel (2008) sugere que se verifique as tendências de mercado, pois podem vir a ser aproveitadas e implementadas atendendo às necessidades contemporâneas, sendo que dessas inclinações mercadológicas é o aumento do consumo da alimentação saudável que cresce a cada dia tornando-se uma tendência mundial. Para Quintella (2017), existem muitas variáveis quando se pretende empreender e todo negócio tem seus riscos, contratempos e complexidades, no entanto o mercado mostra alguns segmentos propícios para empreender e um deles seria o segmento de alimentações saudáveis que possui nichos específicos e cresce a quantidade de interessados.

A preocupação com a saúde e a longevidade está mudando o comportamento dos consumidores, este novo conceito está levando a uma nova tendência de consumo de alimentos, que agora precisam ser saudáveis, nutritivos e/ou funcionais. Com o mercado de produtos naturais e funcionais em alta, a procura deste tipo de alimento está alavancando o mercado e o Brasil já ocupa a quinta colocação no ranking de alimentos e bebidas saudáveis, de acordo com um estudo da agência de pesquisas Euromonitor Internacional, entre 2009 e 2014. O mercado de alimentação voltado à saúde cresceu $98 \%$ neste período. Em 2015, o mercado mundial do setor movimentou mais de US\$ 27 bilhões e nos próximos anos deverá crescer cerca de $20 \%$ (CARREIRO, 2017).

O relatório 'The Top 10 Consumer Trends for 2017', que analisa as tendências de mercado, notou uma inclinação dos consumidores pelos itens considerados saudáveis. Segundo o documento, $83 \%$ dos entrevistados estão dispostos a gastar mais para obter um alimento saudável; 79\% substituem produtos da alimentação convencional por opções mais saudáveis; $28 \%$ acham importante consumir alimentos com alto teor nutricional; $22 \%$ optam por compras alimentos naturais sem conservantes; $44 \%$ dão preferência a produtos sem corantes artificiais; $42 \%$ optam por itens sem sabores artificiais (CARREIRO, 2017).

\section{Alimentos Funcionais e o Chá Verde}

Em meados dos anos 90, no Japão, foi criado o conceito de alimento funcional que recebeu a designação FUSHU (Foods For Specified Health Use - alimento específico para a 
saúde) para alimentos usados em uma dieta normal que demostrem benefícios além dos nutrientes básicos (COSTA; ROSA, 2016)De acordo com a Agência Nacional de Vigilância Sanitária,

Alegação de propriedade funcional é aquela relativa ao papel metabólico ou fisiológico que o nutriente ou não nutriente tem no crescimento, desenvolvimento, manutenção e outras funções normais do organismo humano. Alegação de propriedade de saúde é aquela que afirma, sugere ou implica a existência da relação entre o alimento ou ingrediente com doença ou condição relacionada à saúde (BRASIL, 2013, p.6).

O mercado de alimentos funcionais está ligado a alguns agentes e critérios, como a conscientização dos consumidores, órgãos reguladores que reconheçam o benefício trazido à saúde pública, a ciência governamental, bem como o potencial econômico do produto. Sendo um mercado relativamente novo e com alto potencial de crescimento e diversificação (PIMENTEL, 2018).

Dentre os alimentos funcionais o chá verde (Camellia sinensis) tem sido investigado pelos seus benefícios à saúde. Esse chá teve suas primeiras referências escritas a cerca de 400 a.c., inicialmente era muito utilizado como erva medicinal e só mais tarde, gradualmente, se tornou popular como bebida (HARBOWY M.E, 1997 apud SANTOS, 2016). Tendo em visa que os componentes do chá verde têm potencialidade de promover benefícios à saúde, diversos estudos demostram que o chá verde deve ser considerado um alimento funcional (SENGER, SCHWANKE, GOTTLIEB, 2010).

Com base nos estudos de Senger, Schwanke e Gottlieb (2010), o quadro 1 apresenta alguns estudos envolvendo a administração de chá verde e demostrando resultados positivos do seu consumo.

Quadro 1- Propriedades do chá verde (Camellia sinensis)

\begin{tabular}{|c|c|c|c|c|}
\hline Referência & $\begin{array}{l}\text { Tipo de } \\
\text { estudo }\end{array}$ & População & $\begin{array}{c}\text { Período de } \\
\text { Intervenção e } \\
\text { dosagem }\end{array}$ & Principais resultados \\
\hline \multicolumn{5}{|c|}{ DOENÇAS CARDIOVASCULARES } \\
\hline $\begin{array}{l}\text { Wang et al., } \\
2010\end{array}$ & Caso controle & $\begin{array}{c}520 \text { pacientes (379 } \\
\text { homens e } 141 \\
\text { mulheres) }\end{array}$ & $\begin{array}{l}1 \text { mês (125- } \\
249 \mathrm{~g} / \mathrm{mês} \text { de } \\
\text { folhas secas) }\end{array}$ & $\begin{array}{l}\text { Redução do risco de doença } \\
\text { arterial coronariana em homens, } \\
\text { odds ratio de } 0.62 \text { (95\% CI } 0.38 \text { - } \\
\text { 1.01) comparados com aqueles } \\
\text { que não bebiam o chá verde } \\
\text { (p<0.001). Nas mulheres não foi } \\
\text { encontrado o efeito protetor. }\end{array}$ \\
\hline $\begin{array}{l}\text { Tinahones et } \\
\text { al., } 2008\end{array}$ & Ensaio clínico & 14 mulheres & $\begin{array}{l}5 \text { semanas } \\
(350 \mathrm{mg} \text { de } \\
\text { catequinas, } \\
\text { equivalente a } \\
8,4 \mathrm{~g} \text { de chá } \\
\text { verde) }\end{array}$ & $\begin{array}{l}\text { Melhora na função vascular. A } \\
\text { resposta da artéria braquial a } \\
\text { compressão aumentou de forma } \\
\text { significativa ( } \mathrm{p}<0,0001) \text { após o } \\
\text { tratamento com extrato de chá } \\
\text { verde. Significativa redução } \\
(37,4 \%) \text { na concentração de } \\
\text { LDL oxidada. Redução } \\
\text { significativa na concentração de } \\
\text { Triglicérides }(\mathrm{p}=0,04) \text {. }\end{array}$ \\
\hline
\end{tabular}


Quadro 1- Propriedades do chá verde (Camellia sinensis)

\begin{tabular}{|c|c|c|c|c|}
\hline Referência & $\begin{array}{l}\text { Tipo de } \\
\text { estudo }\end{array}$ & População & $\begin{array}{c}\text { Período de } \\
\text { Intervenção e } \\
\text { dosagem }\end{array}$ & Principais resultados \\
\hline $\begin{array}{l}\text { Yang et al., } \\
2004\end{array}$ & $\begin{array}{c}\text { Estudo } \\
\text { transversal }\end{array}$ & $\begin{array}{l}711 \text { homens e } 796 \\
\text { mulheres com } \\
\text { histórico de } \\
\text { hipertensão }\end{array}$ & $\begin{array}{l}\text { Consumo regular } \\
\text { de chá verde }\end{array}$ & $\begin{array}{l}\text { O consumo diário de } 120-599 \mathrm{ml} \\
\text { de chá verde por dia durante } \\
\text { pelo menos um ano reduziu em } \\
46 \% \text { o risco de desenvolver } \\
\text { hipertensão e o consumo de } \\
\text { mais de } 600 \mathrm{~mL} \text { por dia reduziu } \\
\text { o risco em } 65 \% \text {. }\end{array}$ \\
\hline $\begin{array}{l}\text { Unno et al., } \\
2005\end{array}$ & $\begin{array}{l}\text { Randomizado } \\
\text { controlado e } \\
\text { duplo cego }\end{array}$ & $\begin{array}{c}9 \text { indivíduos com } \\
\text { hipertrigliceridemia } \\
\text { leve }\end{array}$ & $\begin{array}{l}\text { Epigalocatequina } \\
\text { galato em doses } \\
\text { de } 1 \mathrm{mg}, 68 \mathrm{mg} \text { e } \\
243 \mathrm{mg}\end{array}$ & $\begin{array}{c}\text { Quantidades moderadas e } \\
\text { elevadas de catequinas } \\
\text { reduziram níveis de triglicérides } \\
\text { pós-prandiais em } 15,1 \% \text { e } \\
28,7 \% \text {, respectivamente. }\end{array}$ \\
\hline \multicolumn{5}{|c|}{ CÂNCER } \\
\hline Jian et al., 2004 & Caso controle & $\begin{array}{l}130 \text { casos de câncer } \\
\text { de próstata e } 274 \\
\text { controles }\end{array}$ & $\begin{array}{c}\text { Consumo } \\
\text { habitual de chá } \\
\text { verde a longo } \\
\text { prazo }\end{array}$ & $\begin{array}{l}\text { O risco de câncer de próstata foi } \\
\text { inversamente proporcional ao } \\
\text { consumo de chá verde. A odds } \\
\text { ratio, em relação aos não } \\
\text { consumidores de chá, foi } 0,28 \\
\text { (IC } 95 \%=0,17-0,47 \text { ) para } \\
\text { consumidores, } 0,12 \text { (IC } \\
95 \%=0,06-0,26 \text { ), para consumo } \\
\text { há mais de } 40 \text { anos e } 0,09 \text { (95\% } \\
\text { CI=0,04-0,21) para os que } \\
\text { consumiam mais de } 1,5 \mathrm{~kg} \text { de } \\
\text { folhas por ano. }\end{array}$ \\
\hline $\begin{array}{l}\text { Wu AH et al., } \\
2003\end{array}$ & Caso controle & $\begin{array}{l}501 \text { casos de câncer } \\
\text { de mama e } 594 \\
\text { controles }\end{array}$ & $\begin{array}{l}\text { Consumo regular } \\
\text { de chá verde }\end{array}$ & $\begin{array}{l}\text { Redução significativa do risco } \\
\text { de câncer de mama em } \\
\text { consumidoras do chá verde, } \\
\text { mantida após o ajuste de } \\
\text { potenciais fatores de confusão. }\end{array}$ \\
\hline \multicolumn{5}{|c|}{ GLICEMIA } \\
\hline $\begin{array}{l}\text { Fukino et al., } \\
2008\end{array}$ & $\begin{array}{l}\text { Randomizado, } \\
\text { controlado }\end{array}$ & $\begin{array}{l}49 \text { homens, } 11 \\
\text { mulheres com } \\
\text { diabetes bordeline }\end{array}$ & $\begin{array}{l}\text { Consumo extrato } \\
\text { em pó contendo } \\
436 \mathrm{mg} \text { de } \\
\text { catequinas/dia }\end{array}$ & $\begin{array}{l}\text { O hábito de consumo de chá } \\
\text { verde a longo prazo mostrou } \\
\text { relação direta com a diminuição } \\
\text { da gordura corporal e da relação } \\
\text { cintura-quadril. }\end{array}$ \\
\hline \multicolumn{5}{|c|}{ PESO CORPORAL } \\
\hline $\begin{array}{c}\text { Wu CH et al., } \\
2003\end{array}$ & $\begin{array}{c}\text { Estudo } \\
\text { transversal }\end{array}$ & $\begin{array}{l}1103 \text { indivíduos } \\
\text { adultos }\end{array}$ & $\begin{array}{c}\text { Consumo } \\
\text { habitual de chá } \\
\text { verde a longo } \\
\text { prazo (10 anos } \\
\text { ou mais) }\end{array}$ & $\begin{array}{l}\text { O hábito de consumo de chá } \\
\text { verde a longo prazo mostrou } \\
\text { relação direta com a diminuição } \\
\text { da gordura corporal e da relação } \\
\text { cintura-quadril. }\end{array}$ \\
\hline \multicolumn{5}{|c|}{ DECLÍNIO COGNITIVO } \\
\hline $\begin{array}{l}\text { Kuriyama S et } \\
\text { al., } 2006\end{array}$ & $\begin{array}{c}\text { Estudo } \\
\text { transversal }\end{array}$ & $\begin{array}{l}1003 \text { japoneses } \\
\text { idosos }\end{array}$ & $\begin{array}{c}\text { Consumo } \\
\text { habitual de chá } \\
\text { verde }\end{array}$ & $\begin{array}{l}\text { Alto consumo de chá verde foi } \\
\text { associado com menor } \\
\text { prevalência de declínio } \\
\text { cognitivo. }\end{array}$ \\
\hline
\end{tabular}

Fonte: SENGER; SCHWANKE; GOTTLIEB (2010, p.294) 


\section{O Produto Kombucha}

O Kombucha que tem como base o chá-verde (Camellia sinensis) também teve a sua origem na China com registro de 222 d.C. Ele era conhecido como chá da imortalidade. Em 414 d.C. um médico com o nome Kombu teria levado o Kombucha da Côrrea para o Japão para curar os problemas digestivos do Imperador Inkyo e surgia o nome "Kombu chá" ou chá do Kombu (CHEN M.-L. 2002 apud SANTOS, 2016).

No início do século XX, com as expansões das rotas comerciais, o Kombucha veio para o ocidente. Na segunda guerra mundial está bebida já era conhecida em toda a Europa, mas com o racionamento de açúcar, o chá, neste período de guerra, deixou de ser consumido por falta de ingredientes. Em 1960, há relatos de disseminação da informação de que o consumo de Kombucha era tão benéfico como o consumo de iogurte, retomando a popularidade do produto até a atualidade (SANTHISHKUMAR M., 2014 apud SANTOS, 2016).

Sua preparação é feita de chá verde (Camellia sinensis) e uma bolacha gelatinosa de leveduras e bactérias, ficando em repouso entre 7 a 10 dias, e depois pode ser misturado ao suco de uma fruta para dar sabor do chá fermentado.

Comidas e bebidas fermentadas atingem níveis cada vez mais altos de procura, pelas potencialidades que revelam no funcionamento do organismo. A ABIP (2019) anunciou que em 2019 deveria começar a surgir algumas novidades no mercado, como produtos fermentados que resistam mais no tempo. Dentre eles, o Kombucha, que é uma bebida probiótica obtida tradicionalmente a partir da fermentação do chá ou infusões ricas em cafeína (ABIP, 2019).

O Kombucha tem ação probiótica, ajudando nas funções intestinais reforçando as devesas do corpo, há muitos relatos sobre seus efeitos positivos nos organismos, como melhora nas dores de cabeça, redução de peso, diminuição do nível de colesterol, e por esses motivos há vários estudos sobre seus efeitos (LETIERI, 2019). Para Chakravorty et al., (2019) houve, na última década, um notável sentido em entender as propriedades e benefícios do chá fermentado, em vários relatos científicos há afirmações que beber Kombucha pode prevenir diversas doenças, portanto a bebida Kombucha pode ser considerada como uma bebida funcional.

Banerjee et al. (2010) realizaram uma pesquisa com o Kombucha em ratos com úlceras, a fim de verificar a potencialidade de cura de úlceras no estômago após certo tempo de ingestão de Kombucha, revelando que o experimento teve efeito cicatrizante, sendo assim uma potencial formulação anti-ulcerogênica. 


\section{O Teste Conceito}

Para Menshhein (2007) uns dos primeiros passos de um produto novo é o teste conceito, uma vez que este método minimiza os gastos da empresa, podendo ainda na fase inicial do processo fazer alterações e melhorias no produto.

Crawford e Beneditto (2016) alertam que uma das causas de insucesso dos novos produtos é que não são apresentados de forma correta aos consumidores pretendidos, assim eles não veem a necessidade do novo produto, nem o seu valor e objetivo, por isso o teste conceito é uma parte essencial para obter a primeira confirmação do que o produto será, para diminuir o tempo de coleta de informações, para garantir que o produto passe rapidamente pelo desenvolvimento, minimizando o retorno para correção de algum problema e poupando desta forma tempo e custos. Corroborando Cooper (2013) aconselha que antes de seguir em frente com o desenvolvimento do projeto se teste com o cliente, apresentando-lhe o produto, observando seu interesse, gosto e intenção de compra, ele ressalta que sai mais barato testar antes do desenvolvimento final. Ao longo de todo o projeto as contribuições do cliente não devem ser interrompidas antes do término do projeto, testar o conceito do projeto com o cliente tem que ser extremamente iterativo, deixar para testar no final do produto pode ser possível que ocorram surpresas desagradáveis (COOPER, 2013).

Com objetivo de obter o feedback do novo produto, o conceito do produto é apresentado aos consumidores de forma simbólica ou fisicamente por meio de protótipos. Conforme o retorno dos clientes, a empresa consegue analisar a comunicação, a credibilidade, a necessidade do produto, a solução, entre o novo produto e os produtos existentes, o valor percebido pelo cliente e a intenção de compra (KOTLER, 1998). O teste conceito busca demostrar a ideia principal do produto a ser testado para os consumidores, com informações claras e objetivas, assim a empesa pode coletar impressões e percepções para aprofundar o desenvolvimento do produto, bem como reunir subsídios para desenvolver estratégia de comunicação e o posicionamento para o seu lançamento (GONÇALVES, 2016).

Diversas empresas têm por costume testar os conceitos de novos produtos com consumidores antes de transformá-lo efetivamente em produtos definitivos para ofertar ao mercado. O teste pode avaliar o interesse dos consumidores em comprar um determinado produto novo, sua percepção sobre a inovação e diferenças da ideia do produto (KOTLER, ARMSTRONG, 1997).

Para Crawford e Beneditto (2016) o que constitui o termo conceito é o emprego de relações entre o produtor e o consumidor, a partir de uma promessa de um produto. É uma 
proposta real para que o produtor desenvolva uma solução e em contrapartida o consumidor venha a comprar tal solução. Os autores expõem que o teste conceito faz parte do processo de pré-triagem para realização completa da ideia, fornecendo informações para começar o trabalho técnico, sendo o primeiro propósito eliminar o que não for satisfatório para o consumidor, o segundo estimar as vendas mesmo que grosseiramente, ter uma ideia da participação de mercado ou de alcance geral das receitas e o terceiro é ajudar a desenvolver a ideia, pois raramente os conceitos saem do teste de forma que entraram.

Serralvo (2019) orienta que após a clara definição do conceito do novo produto, deve-se proceder o teste conceito, isto é, selecionar um grupo de pessoas, observando que a quantidade de pessoas a serem entrevistadas dependerá do tipo de produto que se está desenvolvendo, do grau de confiança que se quer ter com o teste conceito e os recursos disponíveis para o investimento da pesquisa de mercado.

\section{PERCURSO METODOLÓGICO}

Neste trabalho foi usado a pesquisa exploratória, utilizando a "entrevista com pessoas que tiveram experiências práticas com o problema pesquisado" (GIL, 2002, p.41), bem como, a revisão bibliográfica, por meio de livros, estudos e artigos científicos para levantar informações necessárias da bebida Kombucha e da técnica de pesquisa denominada teste conceito de produto, realizado para saber como o chá poderá ser recebido pelos possíveis consumidores, resultando em dados de aceitação da bebida.

Esta pesquisa foi aconteceu na Fatec Dr. Archimedes Lammoglia, Rua Dom Pedro I, 65 Cidade Nova I, Indaiatuba/SP, na parte da manhã, do dia 3 de outubro de 2019, tendo como amostra/degustadores alunos, funcionários e professores que circulam na Instituição de Ensino. Devido limitações estruturais, a pesquisa se caracteriza como não probabilística por acesso e considerou a quantidade de 100 pessoas que degustaram o Kombucha e em seguida receberam um questionário com as perguntas. Martins e Theóphilo (2007, p.90) explicam que o questionário "é um conjunto ordenado e consistente de perguntas a respeito de variáveis e situações que se deseja medir ou descrever" e Collis e Hussey (2005, p. 165) complementam dizendo que o objetivo do questionário é "descobrir o que um grupo selecionado de participantes faz, pensa ou sente".

O questionário continha 12 questões (Apêndice A), uma pergunta aberta e onze fechadas, era dividido em duas partes: a primeira, com três questões, visava identificar o perfil do entrevistado e a segunda parte, com oito questões, tinha o intuito de descobrir o interesse do entrevistado sobre o novo produto, tendo desenhado as variáveis a partir do conceito de Kotler (1998), dentre estas, cinco utilizaram a escala de medição Likert com 5 pontos, com vista a 
mensurar possíveis atitudes. Becker $(2015$, p.14) explica que a escala de Likert verifica o grau de concordância dos indivíduos, submetidos ao instrumento de coleta de dados,

[...] com cada uma de uma série de sentenças, ou afirmações, possibilitando assim que o pesquisador capture a intensidade de seus sentimentos, ou atitudes, a respeito da temática tratada. Os indivíduos se expressam em escalas simétricas de intensidade, ancorados por expressões verbais variando de grande discordância a grande concordância passando pontos intermediários, rotulados por expressões como alguma discordância, neutralidade e alguma concordância. Atribui-se números de 1-5 (ou de -2 a +2 ) a esses níveis de concordância que, quando totalizados produzem o escore da escala.

No instrumento de coleta de dados do teste conceito do Kombucha, objeto deste estudo, optou-se por utilizar a numeração de 1 a 5 .

Para assegurar que o teste conceito ocorresse de forma adequada organizou-se uma sistematização com três etapas/procedimentos para a devida coleta de dados, como mostra o infográfico a seguir:

Figura 1: Infográfico: sistematização da aplicação do questionário

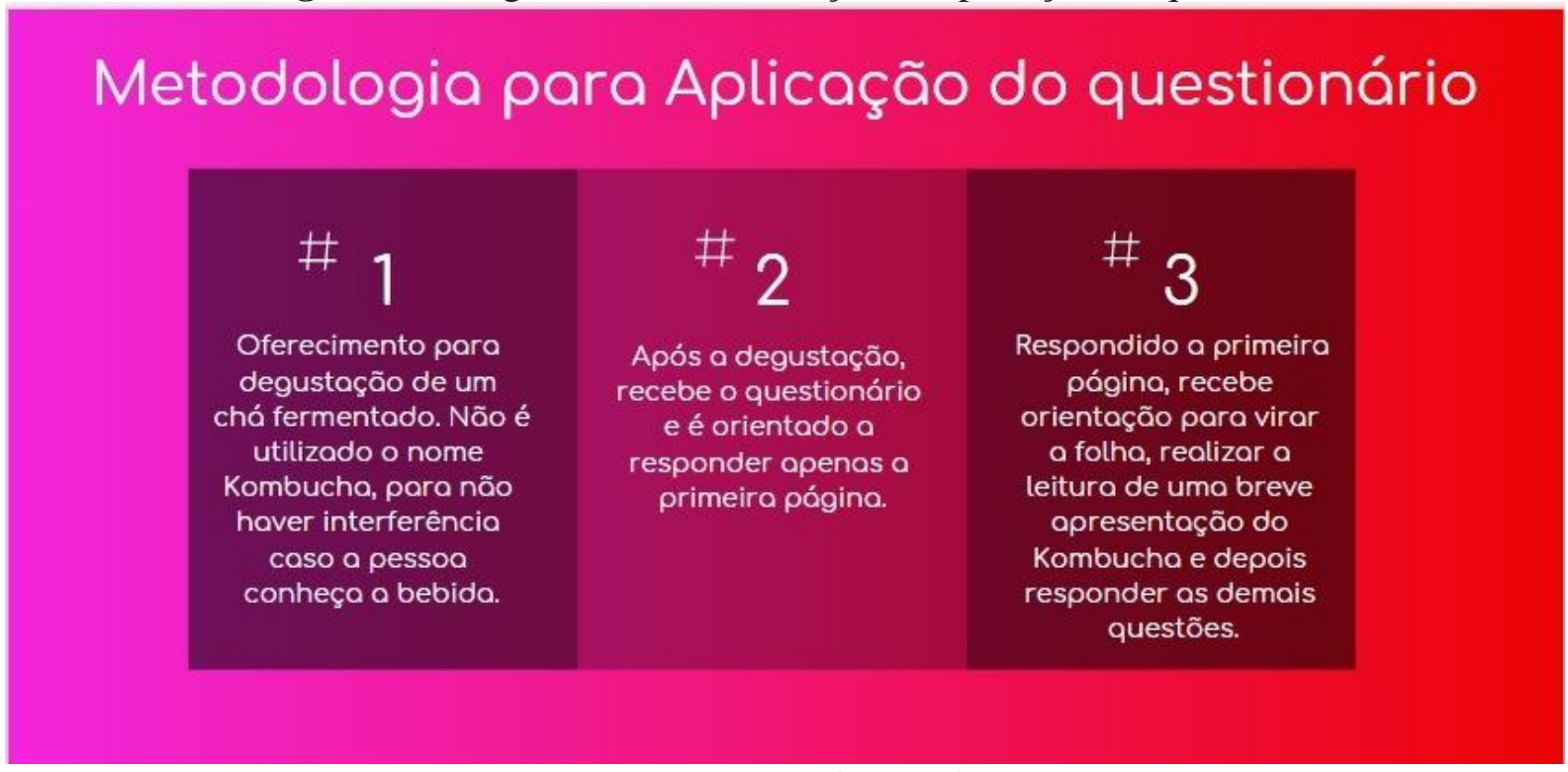

Fonte: Autoria própria.

Paludo (2017) descreveu como fazer o Kombucha para obter os melhores benefícios, na figura 2 está o processo realizado para a fabricação da bebida para o dia da degustação. 
Figura 2: Processo para o preparo do Kombucha

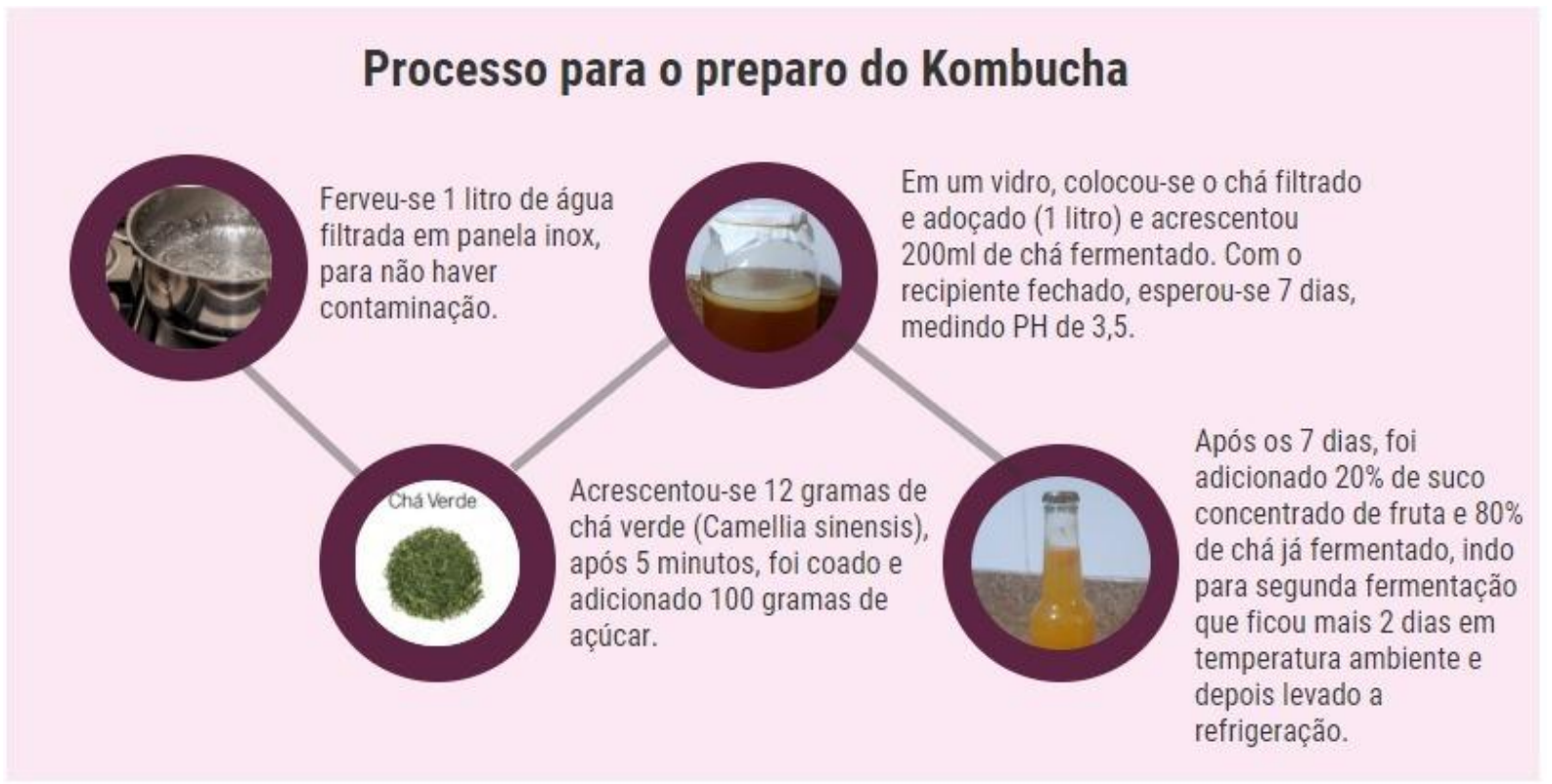

Fonte: Autoria própria, a partir de Paludo (2017).

A análise dos dados coletados é de natureza quantitativa de forma a identificar e quantificar opiniões sobre o Kombucha. As pesquisas quantitativas não só mais atêm-se aos números, mas buscam também socializá-los explicando razões ou testando hipóteses por meio da estatística, assim como a pesquisa qualitativa não trata apenas da interpretação dos fenômenos (GIL, 2002). Para Martins e Theóphilo (2007, p.107) a abordagem de natureza quantitativa implica "organizar, sumarizar, caracterizar e interpretar dos dados numéricos coletados". Os dados foram tratados por meio de estatística descritiva, buscando verificar a frequências das respostas, sendo sua explanação por porcentagens e também disposta em gráfico.

\section{RESULTADO E DISCUSSÃO}

Feita a pesquisa com as 100 pessoas, alunos, professores e funcionários da Fatec Indaiatuba, os resultados do teste conceito respondem ao problema deste paper, referente a aceitação do Kombucha e seu potencial mercado junto a amostra. Tomando por base Menshhein (2007) que orienta que uns dos primeiros passos do produto deve ser o teste conceito, o questionário, com sua sequência de perguntas e aplicação sistematizada, obteve respostas objetivas e sem intervenções de informações externas.

Após a etapa 1, definida na sistematização dos procedimentos de coleta de dados, a degustação do chá fermentado, teve início a etapa 2, que conforme metodologia definida, coletou dados sem revelar ao respondente nenhuma informação sobre o produto experimentado. 
Com objetivo de saber o que mais caracterizava o chá, que até o momento, os respondentes só sabiam que era um chá fermentado, a primeira pergunta foi quantos os adjetivos, que na opinião dos respondentes, melhor descreveriam o chá fermentado. A questão que possibilitava múltiplas respostas, sem limitação máxima de opções a serem assinaladas, apurou os adjetivos mais indicados: Gostoso com 70 indicações; Refrescante 58; Saboroso 48 e Diferente com 50 indicações. Vale registrar que sem indicação nenhuma ficaram os adjetivos: Imitação, Muito Doce, Normal e Ruim. Analisando, de forma geral, o Kombucha teve uma boa aceitação, como mostra a figura 3 .

Figura 3: Adjetivos após a degustação

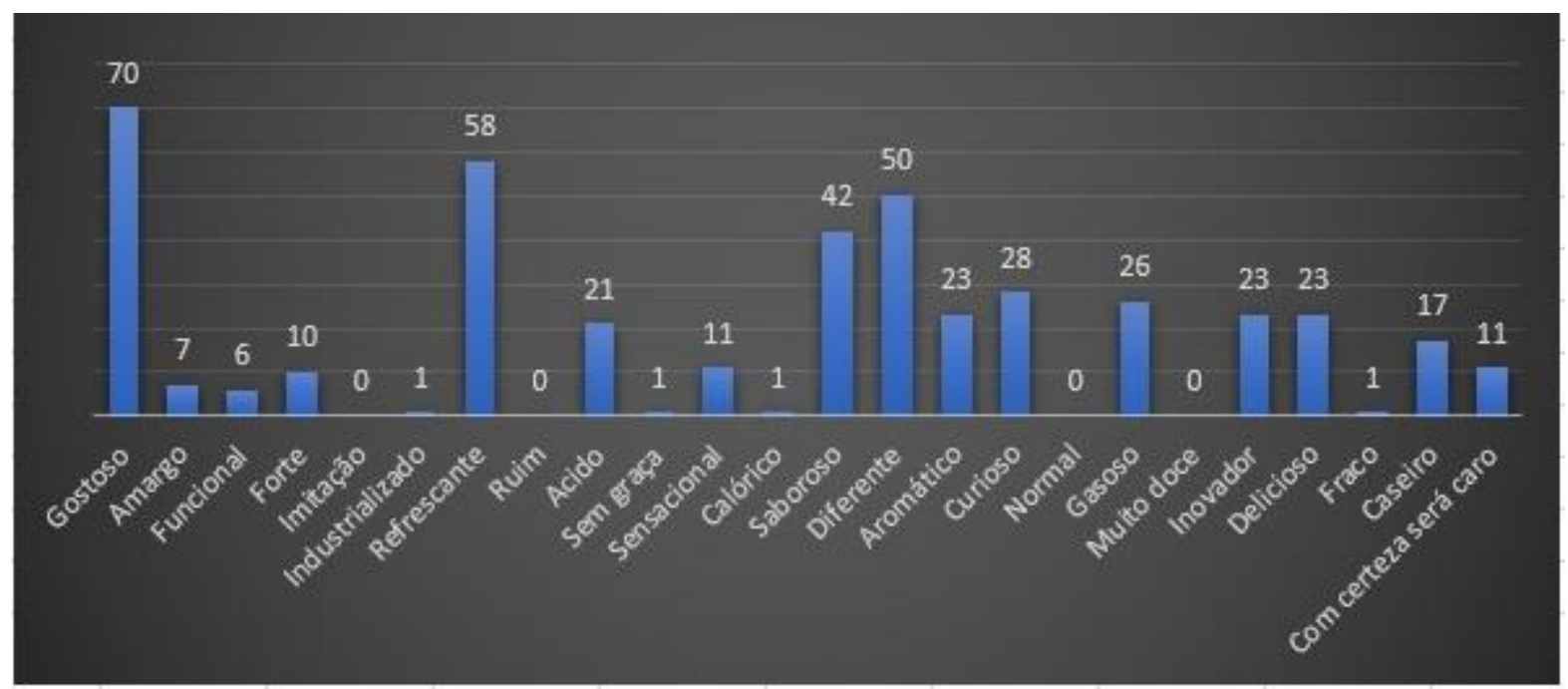

Fonte: Pesquisa de Campo (2019)

Usando a escala de Likert, foi questionado se o produto estivesse no mercado naquele dia a pessoa o compraria, com o objetivo de saber se as pessoas estariam de fato dispostas a comprar o produto. 24 pessoas sinalizaram que, com certeza, comprariam; 43 pessoas provavelmente comprariam, 21 não souberam dizer, assinalando a opção da neutralidade e 10 não comprariam. 2 respondentes não assinaram nenhuma das opções. Analisando os resultados, como base as métricas de Likert, a maioria (67\%) das pessoas comprariam o produto se estivesse a vender no mercado.

Com a mesma escala, perguntou se a pessoa recomendaria a bebida para um amigo ou conhecido, o objetivo desta pergunta foi identificar a aprovação do produto pelos degustadores, para recomendá-lo. O resultado foi que maioria recomendaria (83\%), sendo que 39 com certeza recomendaria e 44 provavelmente recomendaria. Como a recomendação do produto foi mais alta do que as pessoas que comprariam, surge como uma hipótese o ambiente escolar, que talvez transmita confiança aos degustadores para recomendar o produto.

As três próximas perguntas tiveram como objetivo conhecer o perfil do entrevistado. 
Buscou saber como cada respondente considera sua alimentação, com opções de respostas fechadas e uma aberta, caso a pessoa quisesse especificar se não houvesse encontrado uma resposta adequada. $64 \%$ das pessoas responderam ter uma alimentação balanceada comendo de tudo e $23 \%$ assinalaram uma alimentação saudável, dando preferência a produtos naturais (frutas, verduras, legumes, proteínas e carboidratos). Apenas uma pessoa se apresentou como vegana e duas como vegetarianas. Segundo o levantamento do referencial teórico, as pessoas com alimentação balanceada, que comem de tudo, tem potencial de aquisição do Kombucha. Esse dado corrobora ao fato que a maioria declarou ter gostado do produto.

Em relação a faixa etária, a maioria, $60 \%$ pessoas, estavam na faixa etária 18 a 24 anos, 21 tinham entre 25 e 34 anos, 17 estavam entre 35 e 59 anos e 2 tinham 60 anos ou mais. Na questão referente a escolaridade, $76 \%$ dos respondentes registraram superior incompleto e $10 \%$ possuíam superior completo. Tais dados apurados são condizentes ao local e horário da coleta de dados, ambiente universitário, matutino.

Conforme descrito na metodologia, quando os participantes deste estudo terminavam de responder a primeira página do instrumento de coleta de dados (etapa 2), eles eram orientados a virar a página e no outro lado da folha (etapa 3) tinha a explicação do produto degustado, o chá fermentado, no caso o Kombucha e seus benefícios. Essa estratégia foi usada para não haver influência das características funcionais do Kombucha nas primeiras respostas.

Na etapa 3, após a leitura da frase "A bebida que você experimentou se chama Kombucha. É uma bebida probiótica, feita de chá verde, fermentada com leveduras e bactérias, que promove vários benéficos à saúde" o questionamento seguia.

Para saber o quanto a pessoa achou interessante o produto, apresentou a escala de Likert onde 1 era nada interessante e 5 muito interessante. A maioria das pessoas achou muito interessante (57\%) e $34 \%$ considerou interessante a bebida. $9 \%$ marcou a opção 3, demonstrando neutralidade.

Depois foi perguntado sobre o produto ser diferente, utilizando a escala, onde 1 era nada diferente e 5 muito diferente. A maioria (73\%) apontaram que a bebida era diferente, destes 44 respondentes achou muito diferente. 23 demonstraram neutralidade e $4 \%$ não acharam a bebida diferente.

Foi perguntado se era fácil acreditar que o produto oferecia benefícios para saúde. Usando a proposta de Likert, $38 \%$ das pessoas se mostraram neutras nesta questão, mas a maioria (50\%) acredita, sendo que 20 pessoas acreditam totalmente. Novamente, ressurge a hipótese da possível confiabilidade transferida pelo ambiente educacional. No entanto, a soma da neutralidade com a dos descrentes, sinaliza que, caso haja uma comercialização do Kombucha com foco nos 
benefícios funcionais, deve-se levar mais informações para os possíveis consumidores, esclarecimentos sobre o Kombucha e seus benefícios.

Uma pergunta aberta deu a possibilidade para a pessoa que degustou o produto se expressar de uma forma espontânea, para registrar algo que não foi posto pelo questionário. A pergunta foi a seguinte: "O que você mais gostou nessa ideia do produto? Por favor seja o mais detalhista possível e nos diga o que você gostou ou não gostou na proposta da bebida?" As respostas dos participantes estão sintetizadas e são apresentas em forma de nuvem de palavras, conforme Figura 4:

Figura 4: Nuvem de palavras

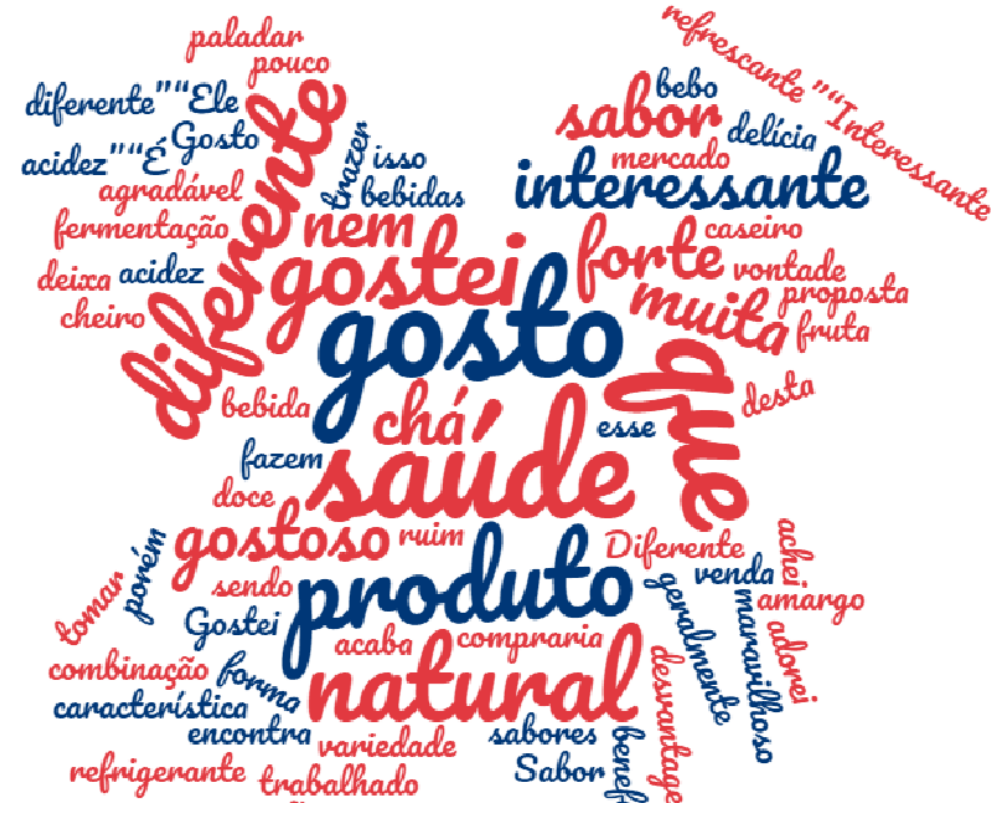

Fonte: Pesquisa de Campo (2019).

Verificou-se que a maioria gostou da bebida, descrevendo um produto interessante, refrescante, natural e diferente, mas também ressaltaram alguns pontos negativos como cheiro forte e acidez. A base do produto é o chá fermentado, acidez e o cheiro são características dos produtos fermentados, porém recomenda-se estudar sabores que diminuam o cheiro e a acidez para que a bebida possa agradar o máximo de pessoas possíveis.

Também foi questionado aos degustadores, caso eles fossem comprar o produto, aonde gostariam de encontrá-lo. A questão de múltiplas respostas, sem limite de opções, identificou que os principais lugares escolhidos pelos entrevistados para comprar o produto, são: supermercado com 72 indicações, lojas de produtos naturais com 60 indicações e 36 indicações para bar e lanchonete. Sabendo onde o consumidor quer encontrar o produto há o direcionamento e distribuição do produto de forma assertiva. 
Figura 5: Estabelecimentos comerciais para o Kombucha

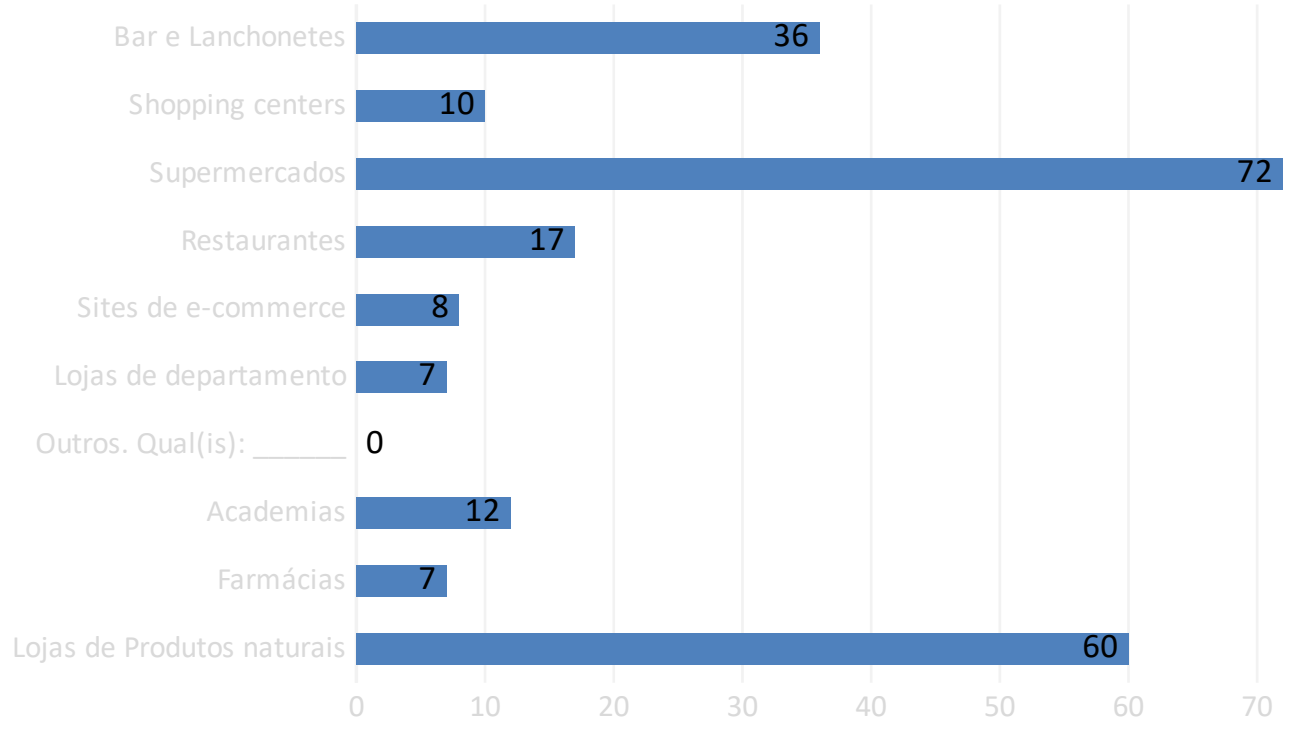

Fonte: Pesquisa de Campo (2019)

A última questão perguntou se os participantes da pesquisa conheciam algum produto similar ao Kombucha, já sendo comercializado no mercado. O objetivo era saber se havia produtos com esta mesma proposta a venda. A maioria, com 45 respostas, disse que não conheciam nenhum e 36 não sabiam dizer. Pode-se considerar que $81 \%$ dos entrevistados não conheciam a comercialização do Kombucha ou similares, o que revela potencial de expansão mercadológica.

\section{CONSIDERAÇÕES FINAIS}

O teste conceito é um dos primeiros passos para saber se um produto vai ser bem recebido pelo mercado consumidor, possibilitando aprimorar, ajustar o produto antes de ser lançado para futuras compras.

Após a degustação da bebida Kombucha e analisados as respostas obtidas pelos questionários ficou evidenciado sua grande aceitação por parte dos entrevistados, que independente da opção alimentar atribuíram a bebida, os adjetivos: gostoso, saboroso, refrescante e diferente. Vale destacar que o Kombucha é uma bebida que, com base no referencial que fundamenta teoricamente esse estudo, teria ainda maior aceitação por pessoas que se dominam veganos ou vegetaríamos, por se tratar de uma bebida natural que promete trazer benefícios a saúde, ratificando o estilo de vida deles. Vale destacar que esse estudo de campo não pretendia definir os possíveis compradores, denominados de prospect em Marketing, e suas características demográficas, idade, sexo, classificação econômica, entre outras e comportamentais, como grupos de referência, consumo de chá ou similares, etc. 
Houve algumas observações em relação ao cheiro e a acidez, diante dessas observações pode-se fazer mais testes de receita e preparo, na tentativa de diminuir esses aspectos e fazer outros testes com sabores mais específicos para descobrir qual sabor agrada o maior número de pessoas possível.

Quando foram questionados se era fácil acreditar nos benefícios da bebida, houve uma neutralidade de $38 \%$, da mesma forma que quando foi perguntado se conheciam algum outro produto similar, as respostas também foram majoritariamente negativas, logo, percebesse que a impopularidade de produtos que ofereçam benefícios faz com que o público seja cético em relação a qualquer outro produto funcional, como Kombucha. Assim, sugere-se para quem for investir na comercialização da bebida levar mais informações, detalhes de sua funcionalidade e benefícios de forma clara para que haja tranquilidade e confiança ao se comprar a bebida.

Caso quisessem comprar a bebida, a maioria optou por comprar em lojas de produtos naturais e supermercados, mas a terceira opção mais votada foi encontrar a bebida em bares e em restaurantes, pois teriam uma bebida diferente e saudável durante ou após as refeições ou até mesmo como uma opção de bebida diferenciada para momentos descontraídos.

A bebida Kombucha surpreendeu a maioria que à experimentou, apresentando potencial de comercialização, mas considerando as observações feitas ao longo da discussão. Por se tratar de uma bebida natural teria um nicho de mercado: pessoas veganas e vegetarianas, mas como este teste mostrou, independente da opção alimentar, as pessoas se identificaram com a bebida. Assim sugere-se ao um futuro investidor que observem estas pessoas que não restringem sua alimentação, mas buscam alimentos que tenham funcionalidades, como os próximos passos recomenda-se fazer novas pesquisas de mercado, uma análise de investimento e o desenvolvimento de uma estratégia de Marketing.

As principais limitações desta pesquisa são o ambiente e os horários da coleta de dados, bem como a amostra com características não probabilística, o que inviabiliza a generalização dos resultados para descrever, em sua totalidade, a aceitação e o potencial de mercado em determinado região comercial.

Como forma de contribuir para futuros estudos, bem como pesquisas mercadológicas, sugere-se testes de desenvolvimento de produto para ampliar sua oferta, como em cápsulas ou em garrafa pet, a realização de um estudo para identificar perfil, interesses e hábitos de consumo dos prospects e pesquisa sobre o nome comercial. Associado a pesquisas que tratam do grau de satisfação do cliente desse tipo de bebida e dos consumidores de chás. 


\section{REFERÊNCIAS}

ABIP - Associação Brasileira da Industria de Panificação e (Org.). Tendências de alimentação para 2019. 2019. Disponível em: <http://www.abip.org.br/site/tendencias-de-alimentacao-para2019/>. Acesso em: 10 set. 2019.

BANERJEE, Debashish et al. Comparative healing property of Kombucha tea and black tea against indomethacin-induced gastric ulce. Food e Funtion, Munbai, v. 1, n. 1, p.284-293, 03 nov. 2010. DOI: 10.1039 / COFO00025F.

BECKER, João Luiz. Estatística: Estática básica transformando dados em informação. Porto Alegre: Bookman, 2015. 479 p.

BRASIL. Agência Nacional de Vigilância Sanitária. Anvisa (Org.). Guia para Comprovação da Segurança de Alimentos e Ingredientes. 2013. Disponível em:

<http://portal.anvisa.gov.br/documents/33916/395734/Guia+para+Comprova\%C3\%A7\%C3\%A3 o+da+Seguran\%C3\% A7a+de+Alimentos+e+Ingredientes/f3429948-03db-4c02-ae9cee60a593ad9c>. Acesso em: 19 set. 2019.

CARREIRO, Juliana. Pesquisas de mercado apontam maior preocupação com alimentação saudável. Comida De Verdade, Estadão. São Paulo, v. 01, n. 01, p.01-01, 03 abr. 2017. Disponível em: https://emais.estadao.com.br/blogs/comida-de-verdade/pesquisas-de-mercadoapontam-maior-preocupacao-com-alimentacao-saudavel/ . Acesso em: 10 set. 2019.

CHAKRAVORTY, Somnath et al. Kombucha: A Promising Functional Beverage Prepared From Tea. Non- Alcoholic Beverages: The Science of Beverages, Estates Unidos, v. 6, n. 1, p.285327, abr. 2019. Https://doi.org/10.1016/B978-0-12-815270-6.00010-4. Disponível em: <https://www.sciencedirect.com/science/article/pii/B9780128152706000104>. Acesso em: 20 set. 2019.

COLLIS, Jill; HUSSEY, Roger. Pesquisa em Administração: um guia prático para alunos de graduação e pós-graduação. 2. ed. Porto Alegre: Bookman, 2005.

CONSIGLIO, Marina. Coquetéis sem álcool, Kombucha e switchel ganham destaque em bares de SP. 2017. Folha UOL. Disponível em: https://guia.folha.uol.com.br/bares/2017/07/coqueteissem-alcool-Kombucha-e-switchel-ganham-destaque-em-bares-de-sp.shtml. Acesso em: 28 ago. 2018.

COOPER, Robert G. Produtos que Dão Certo: Como Criar Valor e Desenvolver Produtos Inovadores. São Paulo: Saraiva, 2013. 448 p.

COSTA, Neusa Maria Brunoro; ROSA, Carla de Oliveira Barbosa. Alimentos Funcionais: componentes bioativos e efeitos fisiologicos. Componentes bioativos e efeitos fisiologicos. 2. ed. Rio de Janeiro: Rubio, 2016. 504 p.

CRAWFORD, Merle; BENEDITTO, Antony di. Gestão de Novos Produtos. 11. ed. São Paulo: Editora McGraw Hill, 2016. 608 p.

E-COMMERCE NEWS, Redação (Ed.). Setor de alimentação saudável deve crescer $\mathbf{4 , 4 1 \%}$ até 2021. 2019. Disponível em: https://ecommercenews.com.br/noticias/balancos/setor-dealimentacao-saudavel-deve-crescer-441-ate-2021/. Acesso em: 03 set. 2019. 
GIL, A. C. Como elaborar projetos de pesquisa. 4. ed. São Paulo: Atlas, 2002.

GONÇALVES, Ana Paula Borges. Coleção Gestão de Marketing: gestão de produtos. Gestão de Produtos. Rio de Janeiro: Editora FGV, 2016.

IBOPE. Sociedade Vegetariana Brasileira (svb). Vegetarianismo: alimentação opinião pública. 2018. Disponível em: https://www.ibopeinteligencia.com/noticias-e-pesquisas/14-da-populacaose-declara-vegetariana/. Acesso em: 23 set. 2019.

KOTLER, Philip. Administração de marketing: Análise. Planejamento, Implementação e controle. São Paulo: Atlas, 1998.

KOTLER, Philip; ARMSTRONG, Gary. Introdução ao Marketing. 4. ed. Rio de Janeiro: Ltc, 1997. $371 \mathrm{p}$.

LETIERI, Rebeca. O que é e como fazer Kombucha: benefícios e origem do chá fermentado probiótico: Globo.com. 2019. Disponível em: <https://globoesporte.globo.com/euatleta/nutricao/noticia/o-que-e-e-como-fazer-Kombucha-beneficios-e-origem-do-cha-fermentadoprobiotico.ghtml>. Acesso em: 20 set. 2019.

MARTINS, Gilberto de Andrade; THEÓPHILO, Carlos Renato. Metodologia da investigação científica para ciências sociais aplicadas. São Paulo: Atlas, 2007.

MASCARENHAS, Karina. Bebida do momento: UFLA desenvolve pesquisas com a Kombucha. 2018. Disponível em: <https://ufla.br/noticias/pesquisa/12485-bebida-do-momentoufla-desenvolve-pesquisas-com-a-Kombucha>. Acesso em: 03 set. 2018.

MENSHHEIN, Rafael Mauricio. Teste de Conceito em Marketing. Portal do Marketing, São Paulo, p.01-01, 05 jan. 2007. Disponível em:

<http://www.portaldomarketing.com.br/Artigos1/Teste_de_Conceito_em_Marketing.htm>. Acesso em: 08 set. 2019.

MISSIAGGIA, Mariana. Os microempreendedores que apostam na moda do

Kombucha. 2018. Disponível em: <https://dcomercio.com.br/categoria/negocios/osmicroempreendedores-que-apostam-na-moda-do-Kombucha>. Acesso em: 02 set. 2018.

PALUDO, Natália. Desenvolvimento e caracterização de Kombucha obtida a partir de chá verde e extrato de erva-mate: processo artesanal e escala laboratorial. 2017. $48 \mathrm{f}$. TCC (Graduação) - Curso de Engenharia de Alimentos, Instituto de Ciência e Tecnologia de Alimentos da Universidade Federal do Rio Grande do Sul, Porto Alegre, 2017.

PIMENTEL, Alex. Curso empreendedorismo. São Paulo: Digerati Books, 2008. 128 p.

PROENÇA, Rossana Pacheco da Costa. Alimentação e globalização: algumas reflexões. Sbpc: Ciência e cultura, São Paulo, v. 62, n. 4, p.0-0, out. 2010. Disponível em: http://cienciaecultura.bvs.br/scielo.php?pid=S0009-67252010000400014\&script=sci_arttext. Acesso em: 26 ago. 2019.

QUINTELLA, Marcus. Empreendedorismo e gestão de negócios. Rio de Janeiro: Synergia Editora, 2017. 220 p. 
RECINE, Elisabetta; RADAELLI, Patrícia (Org.). Alimentação saudável. Brasília, v. 1, p.01-69, nov. 2014. Depto de Nutrição da Faculdade de Ciências da Saúde da Universidade de Brasília (FS/ UnB) e a Área Técnica de Alimentação e Nutrição do Departamento de Atenção Básica da Secretaria de Política de Saúde do Ministério da Saúde (DAB/SPS/MS). Disponível em: <http://bvsms.saude.gov.br/bvs/publicacoes/alimentacao_saudavel.pdf $>$. Acesso em: 19 set. 2019.

REVISTA SUPER VAREJO (São Paulo) (Org.). Saúde já é mais que tendência. 2018.

Disponível em: http://www.supervarejo.com.br/saude-já-e-mais-que-tendencia/ . Acesso em: 19 mar. 2019.

SALGADO, Jocelem. Alimentos funcionais. São Paulo: Oficina de Textos, 2017.

SANTOS, Mafalda Jorge dos. Kombucha caracterização da microbiota e desenvolvimento de novos produtos alimentares para uso em restauração. 2016. 119 f. Dissertação (Mestrado) Curso de Ciências Gastronómicas, Universidade Nova de Lisboa, Lisboa, 2016.

SENGER, Ana Elisa Vieira; SCHWANKE, Carla H. A.; GOTTLIEB, Maria Gabriela Valle. Chá verde (Camellia sinensis) e suas propriedades funcionais nas doenças crônicas não transmissíveis. Scientia Medica, Porto Alegre, v. 20, n. 4, p.292-300, set. 2010.

SERRALVO, Francisco António. Gestão de marcas e produtos. Curitiba: IESDE Brasil S/A, 2009. $172 \mathrm{p}$. 


\section{APÊNDICE A - TESTE CONCEITO DA BEBIDA KOMBUCHA: UM ESTUDO DE MARKETING}

1 Dos adjetivos abaixo, na sua opinião, qual(is) melhor descreve o chá fermentado que você acabou de experimentar? (Marque quantos adjetivos achar necessário)
( ) Gostoso
( ) Refrescante
( ) Saboroso
( ) Muito doce
( ) Amargo
( ) Ruim
( ) Diferente
( ) Inovador
( ) Funcional
( ) Ácido
( ) Aromático
( ) Delicioso
( ) Forte
( ) Sem graça
( ) Curioso
( ) Fraco
( ) Imitação
() Sensacional
( ) Normal
( ) Caseiro
( ) Industrializado
( ) Calórico
( ) Gasoso
( ) Com certeza

será caro

2 Se este produto estivesse disponível hoje no mercado,

2.1 você compraria?

( )

Com certeza não compraria
( ) Provavelmente não
compraria
( )

Não sei dizer

Provavelmente compraria
( )

Com certeza compraria

2.2 você recomendaria ele para algum amigo ou conhecido?

( )

Com certeza não

recomendaria

\section{( )}

Provavelmente não recomendaria
( )

Não sei dizer
( )

Provavelmente recomendaria
( )

Com certeza recomendaria

3 Você considera sua alimentação como?

( ) Balanceada, como de tudo

( ) Saudável, dou preferência a produtos naturais (frutas, verduras, legumes, proteínas e carboidratos)

( ) Calórica, prefiro

( ) Restrita, não como tudo

( ) Vegetariana

( ) Vegana

( ) Nenhuma dessas opções. Por favor, especifique:

4 Qual é sua faixa de idade?
( ) De 18 a 24 anos
( ) De 25 a 34 ano
() De 35 a 44 anos
( ) De 45 a 59 anos
( ) 60 anos ou mais

5 Qual é o seu grau de escolaridade?

( ) Ensino fundamental $/ 1^{\circ}$ Grau (Incompleto)

( ) Ensino fundamental $/ 1^{\circ} \mathrm{Grau}$ (Completo)

( ) Ensino médio $/ 2^{\circ}$ Grau (Incompleto)

( ) Ensino médio $/ 2^{\circ} \mathrm{Grau}$ (Completo)

( ) Superior (Incompleto)

( ) Superior (Completo)

( ) Pós-graduação (Incompleto)

( ) Pós-graduação (Completo)

( ) Não sei ou prefiro não informar

A bebida que você experimentou se chama Kombucha. É uma bebida probiótica, feita de chá verde, fermentada com leveduras e bactérias, que promove vários benéficos à saúde. 
1. Em uma escala de 1 a 5, em que 1 é nada e 5 é muito:

1.10 quanto você achou esse produto?

Nada interessante

\begin{tabular}{|l|l|l|l|l|}
\hline 1 & 2 & 3 & 4 & \multicolumn{3}{|c|}{ Muito interessante } \\
\hline
\end{tabular}

Nada diferente

\begin{tabular}{|l|l|l|l|l|}
\hline 1 & 2 & 3 & 4 & 5 \\
\hline
\end{tabular}

1.2 É fácil acreditar que o produto oferece de benefício para a saúde?

\begin{tabular}{|c|c|c|c|c|} 
Totalmente & \multicolumn{3}{c}{ Acredito } \\
\hline 1 & 2 & 3 & 4 & 5 \\
\hline
\end{tabular}

$2 \mathrm{O}$ que você mais gostou nessa ideia do produto? Por favor seja o mais detalhista possível e nos diga o que você gostou ou não gostou na proposta da bebida?

3 Caso fosse comprar este produto hoje, onde você iria procurá-lo? Marque quantas alternativas quiser.
( ) Lojas de Produtos naturais
( ) Lojas de departamento
( ) Supermercados
( ) Farmácias
( ) Sites de e-commerce
( ) Shopping centers
( ) Academias
( ) Restaurantes
( ) Bar e Lanchonetes
( ) Outros. Qual(is):

4 Você conhece algum produto similar a este, já sendo comercializado no mercado?

( ) Sim, vários

( ) Sim, alguns

( ) Sim, apenas um

( ) Não, nenhum

( ) Não sei dizer 